\title{
Comparison between Friction Stir and Submerged Arc Welding applied to Joining DH36 and E36 Shipbuilding Steel
}

\author{
Stephen Cater ${ }^{1}$, Jonathan Martin ${ }^{1}$, Alexander Galloway ${ }^{2}$, Norman McPherson ${ }^{3}$ \\ ${ }^{1}$ TWI Technology Centre (Yorkshire) Ltd, Rotherham, S60 5TZ, United Kingdom \\ ${ }^{2}$ University of Strathclyde, Glasgow, G1 1XJ, United Kingdom \\ ${ }^{3}$ BAE Systems Surface Fleet, Glasgow, G51 4XP, United Kingdom \\ Friction, FSW, submerged arc, steel, DH36, E36, butt, shipbuilding
}

\begin{abstract}
With the impending development of FSW tools for steel with useful lifetimes, attention has turned to the mechanical properties of the welds that can be made in a range of industrially significant steels. This work reports on a comparative study undertaken to examine the use of friction stir and submerged arc welding on DH36 and E36 shipbuilding steels. The study made an assessment of the distortion induced in fabricating plates by the two welding techniques, and provides initial comparative data on weld tensile strength, toughness and fatigue life. In each case, friction stir welding was shown to outperform submerged arc welding.
\end{abstract}

\section{Introduction}

Friction stir welding is an established process widely used for the fabrication of safety critical structures in aluminium, magnesium and copper alloys across many market sectors. It is recognised that in these materials the process brings benefits in terms of weld integrity, durability, fatigue life and reduced cost when compared with conventional fusion welding techniques. Until recently, the transfer of this capability into the steel sector was stalled by the relatively poor performance and high cost of the tools required. This situation is now changing, with composite pcBN/W-Re FSW tools becoming available that are capable of producing industrially useful lengths of welds in steel. Friction stir welding (FSW) is therefore a joining technique of interest to Shipbuilders who are attempting to identify low distortion joining methods that will allow cost-effective fabrication of steel sheets. Using conventional arc welding methods causes significant amount of distortion that relate to increased costs associated with fitup, fabrication and installation. However any adopted welding technique must also produce joints with at least comparable tensile, fatigue and impact performance.

The work detailed below shows the developmental progression of applying FSW to butt welding of two shipbuilding steels and assessing the joint performance. The two steels selected are DH36 and E36 which are carbon manganese niobium steels with a minimum yield strength of $360 \mathrm{~N} / \mathrm{mm}^{2}$ and a minimum impact requirement of $36 \mathrm{~J}$ at $-20^{\circ} \mathrm{C}$ and $-45^{\circ} \mathrm{C}$ respectively.

There has been previous work in this area (1) which concluded that there was a capability to produce single pass full penetration FSW welds in $6.4 \mathrm{~mm}$ thick steel plate. The steel used was not C-Mn-Nb but a C-Cr-Mo-V steel. Increasing the travel speed resulted in a progressive increase in weld metal hardness to a maximum level of $350 \mathrm{Hv}$, which is close to the acceptable maximum. The all weld metal mechanical properties appeared to be acceptable with yield and tensile strengths well above the base plate. However, the elongation was below specification and was a function of the welding speed. There was no description of the toughness of the steel. On 
the basis of hardness and elongation it could be predicted that there was probably an issue in achieving the specification requirements. Another publication (2) alludes to a problem meeting the toughness requirements for DH36. However in that same publication (2), there appeared to be a potential to have better toughness when welding HSLA 65. The work did however show that lower distortion was produced from FSW processed material. An additional publication (3) from the same source highlighted the benefits of FSW as being, less in need for fume extraction and having lower distortion.

\section{Summary of Initial Work Programme}

An initial study was carried out in $2012^{[4]}$ comparing butt welding of DH36 steel using FSW and submerged arc welding techniques. Distortion was found to be lower in friction stir welded steel plates of 4, 6 and $8 \mathrm{~mm}$ thickness than in equivalent submerged arc welded (SAW) plates as shown in Figures 1 to 3 and listed in Table 1. Also no issues were identified with weld metal strength, and Charpy impact toughness at $-20^{\circ} \mathrm{C}$ which was found to be comparable but more uniform across the weld area than with the submerged arc welded material. Microstructural observations were linked to hardness, toughness and fatigue test data.

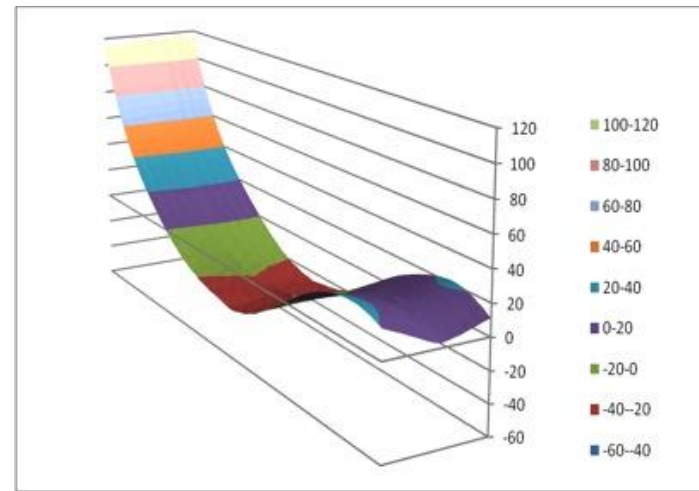

a)

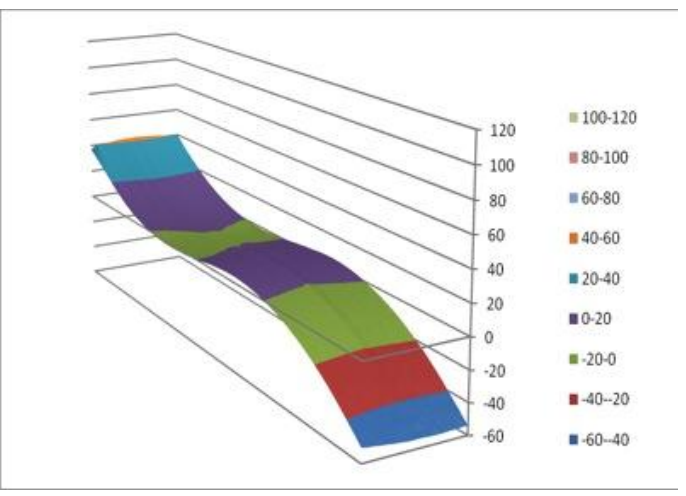

b)

Figure 1 Distortion comparison between 4mm thickness DH36 steel plates, 2000 x 400mm, butt welded along the $2000 \mathrm{~mm}$ edge:

a) SAW;

b) FSW.

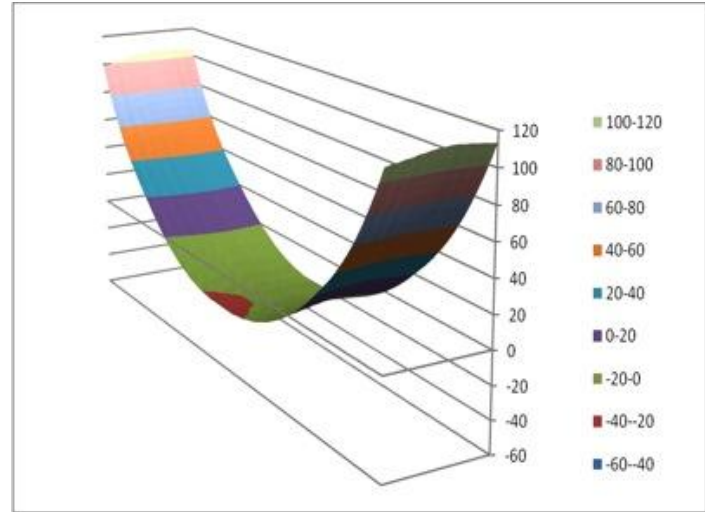

a)

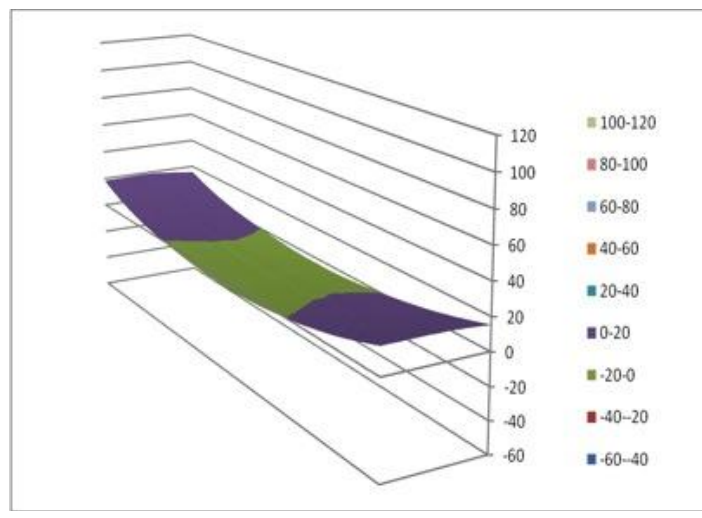

b)

Figure 2 Distortion comparison between 6mm thickness DH36 steel plates, $2000 \mathrm{x} 400 \mathrm{~mm}$, butt welded along the $2000 \mathrm{~mm}$ edge:

a) SAW;

b) FSW. 


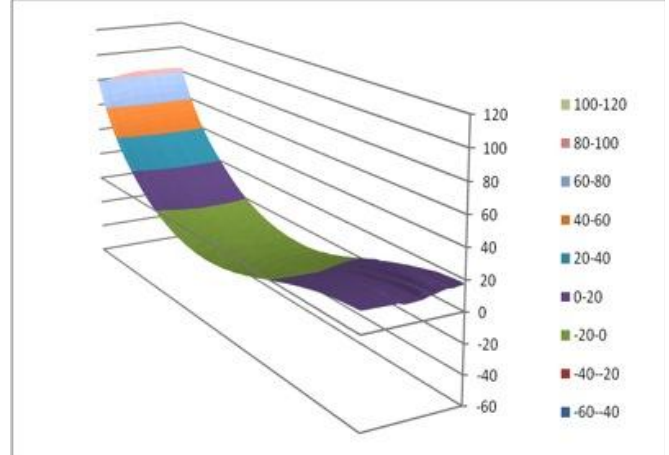

a)

Figure 3 Distortion comparison between $8 \mathrm{~mm}$ thickness DH36 steel plates, 2000 x 400mm, butt welded along the $2000 \mathrm{~mm}$ edge;

a) SAW;

b) FSW.

Table 1 Summary of distortion in DH36 steel plates butt welded along the $2000 \mathrm{~mm}$ edge.

\begin{tabular}{|l|l|l|}
\hline Plate thickness, $\mathrm{mm}$ & $\begin{array}{l}\text { Distortion over 2000mm } \\
\text { submerged arc welded plates }\end{array}$ & $\begin{array}{l}\text { Distortion over 2000mm } \\
\text { friction stir welded plates }\end{array}$ \\
\hline 4 & 120 & 60 \\
\hline 6 & 110 & 20 \\
\hline 8 & 80 & 15 \\
\hline
\end{tabular}

The fatigue properties reported showed the FSW plates to outperform the SAW plates. A typical result is shown in Figure 4.

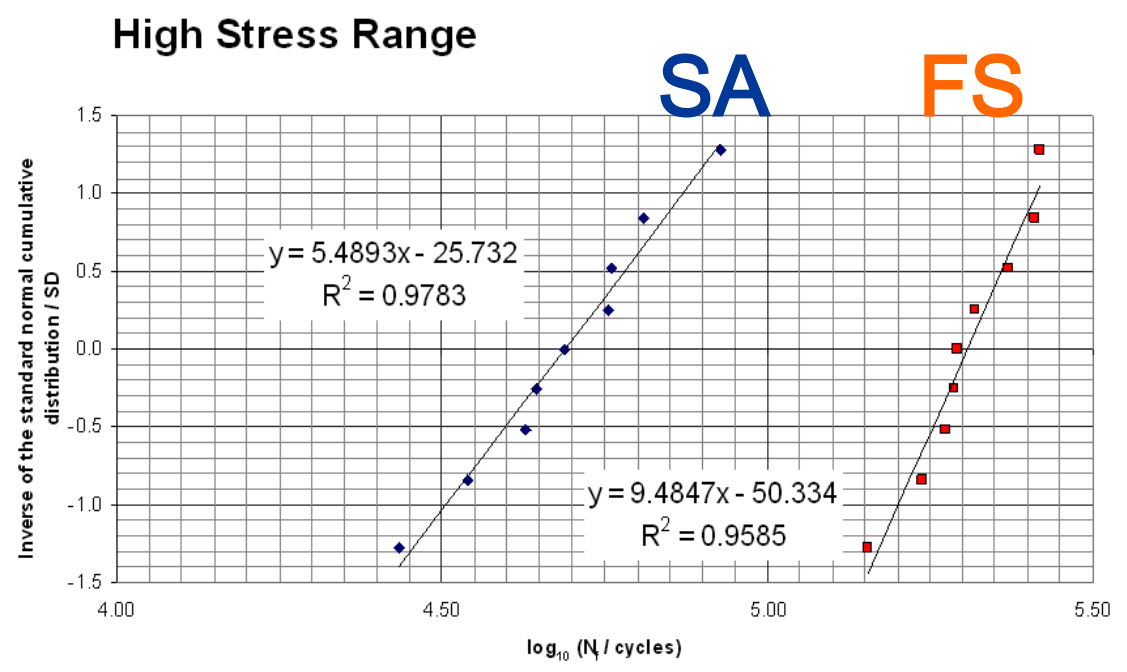

Figure 4 Comparison of high stress fatigue properties of SAW and FSW DH36 steel.

Further work ${ }^{[5]}$ showed that double sided FSW of 8mm DH36 surprisingly gave an increase in the level of distortion from 15 to $25 \mathrm{~mm}$ as shown in Figure 5 

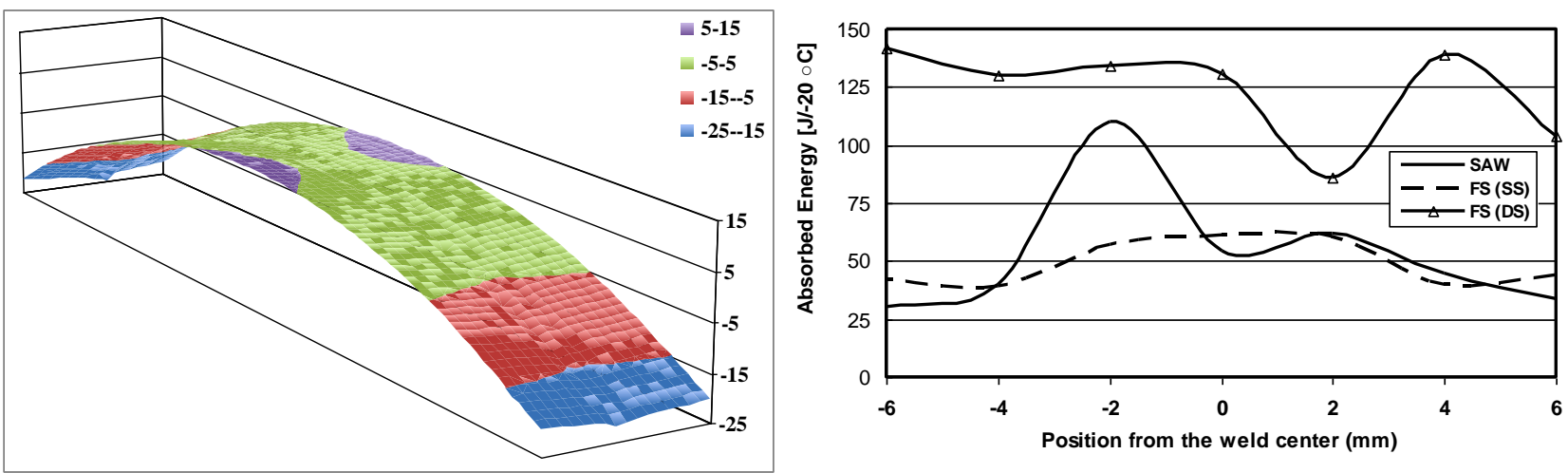

Figure 5 Distortion measurement of $8 \mathrm{~mm}$ Figure 6 Absorbed energy along the weld joint thickness DH36 steel plates, 2000 x 400mm, double sided butt welded along the $2000 \mathrm{~mm}$ edge;

This work also showed that a double sided FSW weld has the potential to improve the weld toughness over the single sided FSW and SAW as shown in Figure 6 however further investigation and data was required.

\section{Comparable studies in E36 Steel}

To compare these properties and obtain further supporting data a second steel grade is being investigated namely, E36, a tough, moderate strength (355MPa) steel used for marine construction, particularly ship hulls and superstructures, and offshore structures such as oil rigs.

\section{Experimental Approach}

Six friction stir welded plates were produced by joining overall plate dimensions of $6 \mathrm{x} 400 \mathrm{x}$ $2000 \mathrm{~mm}$. The nominal chemical analysis of the parent plate is shown in Table 2.

Table 2 Chemical analysis of parent plate

\begin{tabular}{|l|l|l|l|l|l|l|l|l|l|l|l|l|l|}
\hline$\% \mathrm{C}$ & $\% \mathrm{Si}$ & $\% \mathrm{Mn}$ & $\% \mathrm{P}$ & $\% \mathrm{~S}$ & $\% \mathrm{~N}$ & $\% \mathrm{Al}$ & $\% \mathrm{Ti}$ & $\% \mathrm{Cu}$ & $\% \mathrm{Cr}$ & $\% \mathrm{Ni}$ & $\% \mathrm{Mo}$ & $\% \mathrm{Nb}$ & $\% \mathrm{~V}$ \\
\hline 0.13 & 0.31 & 1.45 & 0.011 & 0.001 & 0.004 & 0.048 & 0.02 & 0.05 & 0.03 & 0.04 & 0.004 & 0.03 & 0.004 \\
\hline
\end{tabular}

\section{Welding}

The FSW plates were welded at the TWI Technology Centre (Yorkshire), UK. The plates were welded using the 'as received' faces as the faying edges in order to determine the effect of no preparation of the edges upon weld quality. No milling of the plates was undertaken to ensure that they were of uniform thickness or remove any surface scale and inclusions. Some plates were given a light dressing along the weld line with a sanding disc on an angle grinder prior to welding to remove excessive mill scale but no attempt was made to fully remove the scale and take the plate back to bare metal of uniform thickness. This preparation regime was adopted to investigate how robust the FSW process is for industrial applications. A picture of the welding set up is shown in Figure 7

The FSW tools used in this study were manufactured by MegaStir Inc. from a composite ceramic material: refractory metal designated Q70. This material contains $70 \%$ by volume of 
polycrystalline boron nitride in a tungsten-rhenium binder. The tool design comprises of a stepped spiral probe and scroll shoulder, made from a single piece of pcBN-WRe composite, mechanically held in a metal shank. An argon gas shield was also used, more to protect the tool rather than the surface area of the welded region.

One plate was welded from just one side to give a full penetration through thickness weld whilst other plates were welded from both sides. These double-sided welded plates had different degrees of weld zone overlap as indicated in Table 3. There were two reasons for the manufacture of double-sided plates:

1. FSW is currently limited in the thickness of steel that can be welded by the size of FSW tool that can be manufactured from the pcBN-WRe composite and thus for the foreseeable future welds in steels thicker than $8 \mathrm{~mm}$ will need to be made as double sided welds

2. There are indications from the initial work reported by McPherson et al that double sided welds may have superior properties to single sided welds.

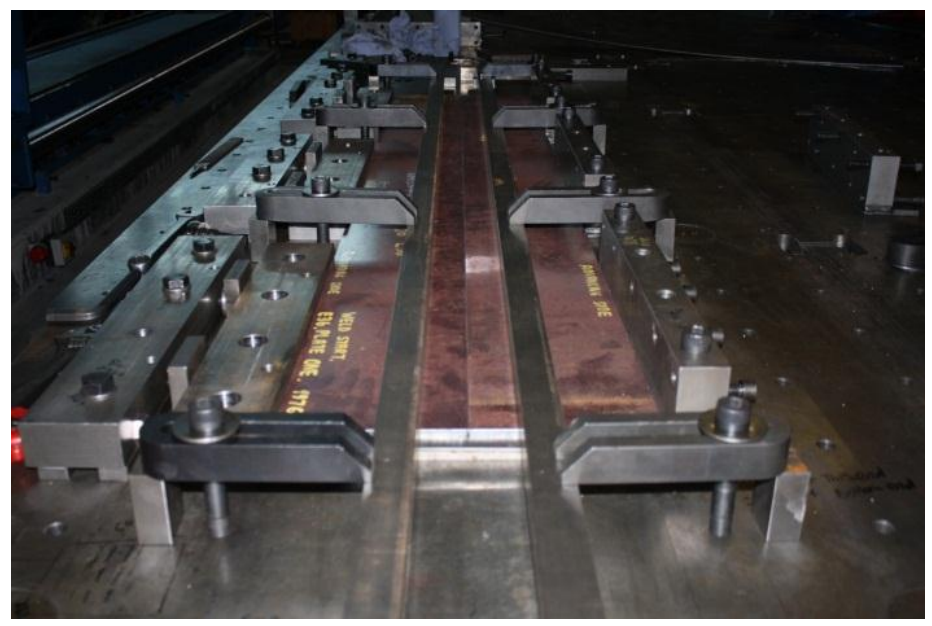

TWI Image SYF 19673-5150

Figure 7 Image showing two plates of E36 steel clamped into the welding jig prior to welding.

As far as possible, the welds used similar welding parameters based upon those reported to give good welds in the initial work programme when welding DH36. For all the double sided welds, the second weld was made on the reverse of the plate in the opposite traverse direction to the first weld in order to even out the asymmetry of the FSW process. (That is, the advancing side of the second weld was over the retreating side of the first weld).

Table 3 Details of weld set up and preparation for each plate

\begin{tabular}{|l|l|l|l|}
\hline Plate Ref & Type of weld & $\begin{array}{l}\text { Overlap zone, } \\
\mathrm{mm} / \%\end{array}$ & Plate preparation note \\
\hline Plate 1 & $\begin{array}{l}\text { Double sided, 6mm, full } \\
\text { penetration from both sides }\end{array}$ & $6 / 100$ & $\begin{array}{l}\text { Joint line lightly sanded prior to } \\
\text { welding }\end{array}$ \\
\hline Plate 2 & $\begin{array}{l}\text { Double sided, 6mm first } \\
\text { then 4mm on reverse. }\end{array}$ & $4 / 66$ & $\begin{array}{l}\text { Joint line lightly sanded prior to } \\
\text { welding }\end{array}$ \\
\hline Plate 3 & $\begin{array}{l}\text { Double sided, 4mm then } \\
\text { 4mm. }\end{array}$ & $2 / 33$ & $\begin{array}{l}\text { Minimal surface preparation - } \\
\text { wipe with Scotchbrite }\end{array}$ \\
\hline Plate 4 & Double sided, 4mm first & $1 / 16.6$ & No surface preparation \\
\hline
\end{tabular}




\begin{tabular}{|l|l|l|l|}
\hline & then 3mm on reverse & & \\
\hline Plate 5 & $\begin{array}{l}\text { Double sided, 3mm first } \\
\text { then 4mm on reverse }\end{array}$ & $1 / 16.6$ & Minimal surface preparation \\
\hline Plate 6 & $\begin{array}{l}\text { Single sided, 6mm, full } \\
\text { penetration }\end{array}$ & $0 / 0$ & $\begin{array}{l}\text { Surface lightly prepared with } \\
\text { sanding wheel }\end{array}$ \\
\hline
\end{tabular}

\section{Testing}

All the plates were measured for distortion. Plates 1, 3 and 6 were subjected to further tests as shown below. These plates were selected to represent the range of tool penetration from singlesided through thickness to double-sided welds having full and partial tool zone overlaps.

- Cross weld tensile strength

- Weld centreline Charpy toughness

- Fatigue testing

\section{Distortion measurement}

The plates were assessed for distortion using a laser measurement scanner at the University of Strathclyde. The plates were marked with the position of 4 identical reference points coinciding with the position of the mounting points, to ensure that all the plate measurements were consistent with each other. The plates were then lifted on to the measurement platform and aligned on to the four mounting points.

The overhead travelling laser was then aimed at the bottom left corner of the plate and programmed to measure the position of the plate surface over a series of 6370 longitudinal and 2530 lateral steps. (The welded plates were $2000 \mathrm{~mm}$ long by $400 \mathrm{~mm}$ wide.) It then took around 10 minutes for the laser to scan each plate. After the laser had finished scanning each plate, the data were stored in a file compatible with subsequent analysis in Excel. Distortion was defined as the deviation from a plane bounded by the four reference points. Prior to welding, all the plates were flat.

The measured distortions are presented in Table 4 below, and a typical distortion map is presented in Figure 8.

Table 4 Measured plate distortion.

\begin{tabular}{|l|l|l|l|}
\hline Plate & $\begin{array}{l}\text { Overlap } \\
\text { zone, } \%\end{array}$ & Type of weld & $\begin{array}{l}\text { Maximum } \\
\text { distortion, } \mathrm{mm}\end{array}$ \\
\hline 1 & 100 & Double & 9.5 \\
\hline 2 & 66 & Double & 17.5 \\
\hline 3 & 33 & Double & 10.5 \\
\hline 4 & 16 & Double & 22 \\
\hline 5 & 16 & Double & 22 \\
\hline 6 & 0 & Single & 20.2 \\
\hline
\end{tabular}




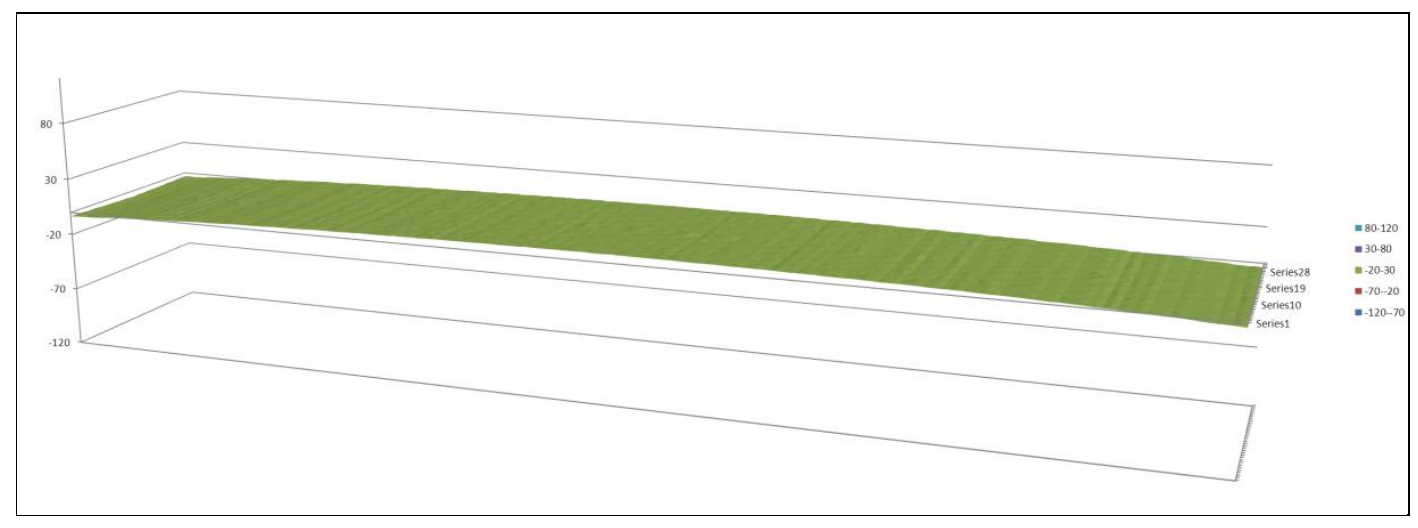

Figure 8 Typical distortion map of E36 plate. Maximum measurement in middle of plate.

All the plates distorted by arching upwards in the centre of the plate with the last weld uppermost.

The results obtained in this study confirmed the earlier work reported by McPherson et al indicating that FSW induces far less distortion in carbon steel weldments than does submerged arc welding. As may be seen from Table 4, all plates exhibited a total distortion of less than $22 \mathrm{~mm}$ over the $2000 \mathrm{~m}$ length. By way of comparison, the FSW 6mm thickness DH36 plate had a similar magnitude of distortion $(20 \mathrm{~mm})$ but the SAW plate was significantly more distorted, almost $110 \mathrm{~mm}$. It is considered that the primary reason for this is the lower thermal energy input to a friction stir weld and the lack of volume changes that occur during the melting and solidification cycle of a fusion weld. There may be a further, though lesser, contributory effect from the fact that plates welded by friction stir techniques are clamped very rigidly in place throughout the welding process. The different microstructures that can be generated by FSW may change the volumetric variations and thus residual stresses present in the weld zone, perhaps further reducing distortion. Finally, any residual stresses in the weld will also be influenced by a second pass of the tool in double welded samples though from the limited number of samples in this study it is not possible to identify with certainty the presence and magnitude of this effect.

\section{Tensile testing}

To determine the strength of the welds made, cross weld tensile tests were performed on samples from the welded plates in accordance with EN ISO 6892-1:2009. The testing was performed by Exova (UK) Ltd.

Table 5 Tensile strength of friction stir welds

\begin{tabular}{|l|l|l|l|}
\hline Plate & Degree of overlap & $\begin{array}{l}\text { UTS, } \\
\text { MPa }\end{array}$ & Comment \\
\hline 1 & 100 & 561 & Parent break \\
\hline 3 & 33 & 576 & Parent break \\
\hline 6 & 0 & 574 & Parent break \\
\hline
\end{tabular}

All the tensile test specimens failed in the parent plate. The tested samples had an average strength of $570 \mathrm{MPa}$ indicating that the welds were at least as strong as parent material and in all cases exceeded that minimum material strength by a significant margin. The presence of defects in some of the welds tested did not appear to have too great a detrimental effect upon weld 
strength. In those cases where surface oxides were not removed from the faying edges before welding, it appears that the tool broke up these layers and distributed them as small particles throughout the weld zone.

The degree of grain refinement that can take place in a friction stir weld is clearly shown by Figure 9 which shows a comparison between the grain sizes in the parent material and the TMAZ of a weld in E36 steel.

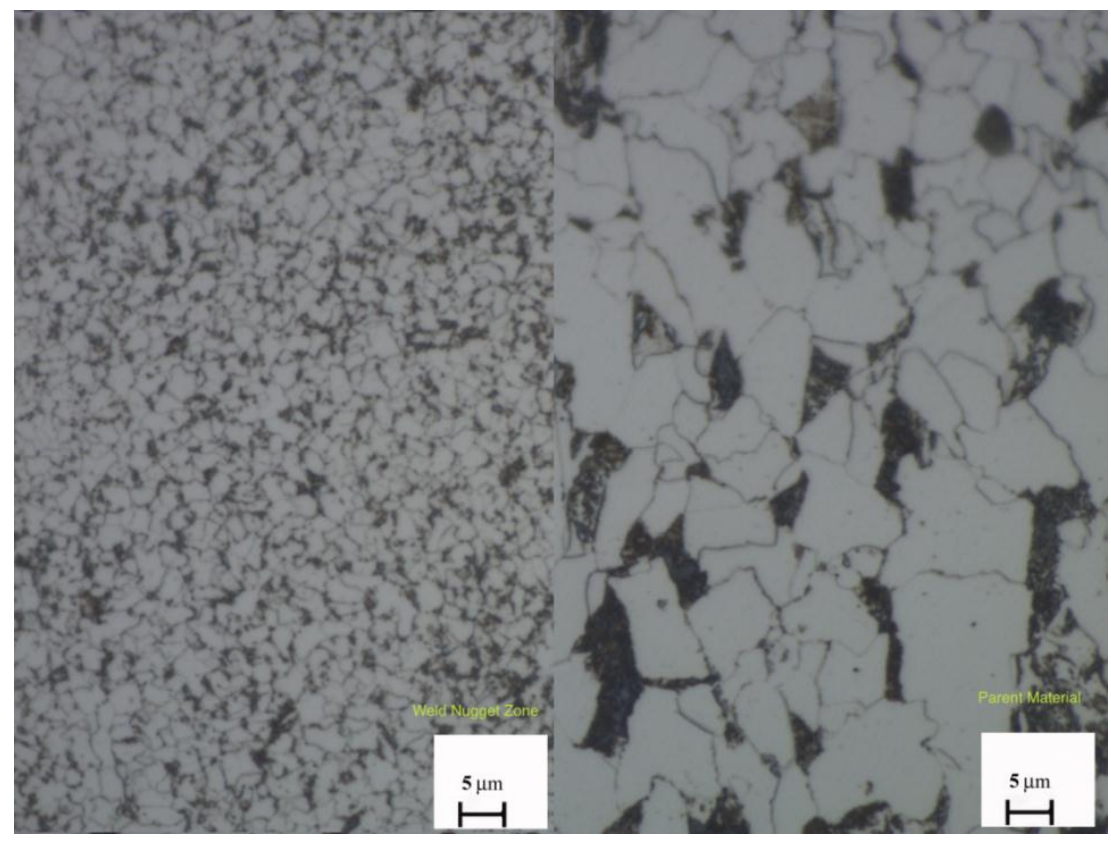

Figure 9 Comparison of grain size in the TMAZ and parent material in E36 steel.

\section{Charpy toughness}

The toughness of the selected welds was determined by Charpy impact testing, performed according to ISO $148-1: 2009(\mathrm{KV} 2)$ at $-45^{\circ} \mathrm{C}$. Test samples $10 \times 5 \times 2 \mathrm{~mm}$ were taken from the weld centreline, and also from positions offset from either side of the weld centreline by 2, 4 and $6 \mathrm{~mm}$. FSW is an asymmetric process and thus it was deemed appropriate to establish the toughness properties of the weld across the full width of the weld zone. The Charpy impact toughness data for three of the E36 steel plates are plotted in the Figure 10. The data are for the plates with a single sided weld ( $0 \%$ overlap), a double sided weld with a $33 \%$ and $100 \%$ stir zone overlap.

For the three tested, the toughness was greater in the thermomechanically affected zone (TMAZ) than in the heat affected zone (HAZ). The toughness distribution appears to be asymmetric.

The data indicate that the Charpy impact toughness at $-45^{\circ} \mathrm{C}$ in the single side welded plate, ie full penetration with no overlap zone, is similar to that expected from unwelded parent material at around 50J. Both the plates that had been welded from both sides (33\% and 100\% overlap of the weld zones) exhibited a higher toughness level, close to 100J. 


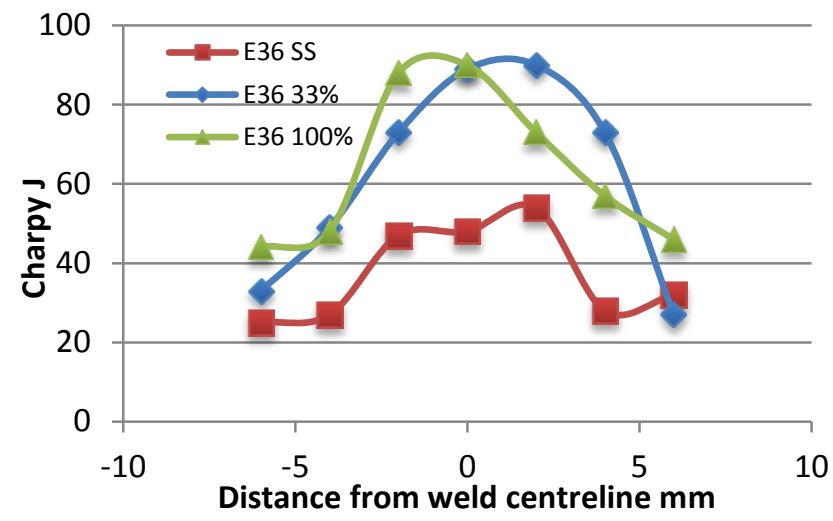

Figure 10 Charpy impact toughness profile at $-45^{\circ} \mathrm{C}$ for $\mathrm{FSW} \mathrm{E} 36$ steel plates 1,3 and 6

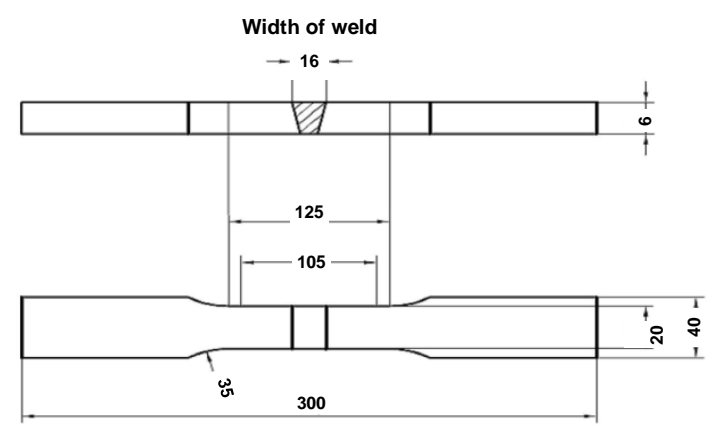

Figure 11 Dimensions of fatigue test piece.

This may be explained in part by the microstructural changes wrought by the FSW process. FSW has produced a microstructure with a much finer grain size in the thermomechanically processed zone and the second pass will have had a tempering effect upon the material in the first weld zone. The initiation and propagation of crack through the complex microstructure present in these E36 friction stir weld zones will therefore require more energy than in coarse grained microstructures typical of a conventional fusion weld.

\section{Fatigue testing}

Fatigue testing was performed at the University of Strathclyde. Two fatigue testing machines were used, one an Instron 8801 and the second an Instron 8802. These feature precision-aligned, high-stiffness load frames that encompass a broad range of static and dynamic test applications. The two machines differ in that the 8801 has an axial force capacity of $100 \mathrm{kN}$ whilst the 8802 has a capacity of $500 \mathrm{kN}$.

Standard 'dog bone' fatigue test samples were cut from the selected welded plates using an automatic milling machine and their cut edges de-burred. The form and dimensions of the samples are shown in Figure 11. Seven samples were prepared per plate. Three samples were used for both high and low cycle fatigue (HCF and LCF respectively) and one was used to determine the yield stress of the material so that the parameters for the fatigue tests could be determined accurately for each material. It was decided that the LCF test would be run at $95 \%$ of the first yield stress and that the HCF test would be run at $60 \%$ of the first yield stress. However, after considering the timescale of the project and given that the first batch of HCF tests ran on for over a million cycles, it was decided that a more appropriate stress level would be at $80 \%$ of the first yield stress. Fatigue testing of the selected specimens is currently underway. The available results are shown in Table 7 below.

Table 7 Preliminary fatigue test results for E36 steel specimens.

\begin{tabular}{|l|l|l|l|}
\hline Plate & Stress & $\begin{array}{l}\text { Cycles to } \\
\text { failure }\end{array}$ & Comment \\
\hline & & & $\begin{array}{l}\text { No failure. This sample was then cycled at } \\
80 \% \text { yield and failed at the advancing edge } \\
\text { after a further 17,000 cycles }\end{array}$ \\
\hline E36-0\% overlap & $60 \%$ yield & $1,800,000$ & $\begin{array}{l}\text { No failure. This sample was then cycled at } \\
80 \% \text { yield and failed at the retreating edge }\end{array}$ \\
\hline
\end{tabular}




\begin{tabular}{|l|l|l|l|}
\hline & & & after a further 58,566 cycles \\
\hline E36 - 0\% overlap & $60 \%$ yield & 374,797 & Failed on advancing edge of weld \\
\hline E36 - 0\% overlap & $95 \%$ yield & 170,000 & Failed on advancing edge of weld \\
\hline E36 - 0\% overlap & $95 \%$ yield & 100,000 & Failed on advancing edge of weld \\
\hline E36 - 33\% overlap & $95 \%$ yield & 495,815 & Parent material failure \\
\hline E36 - 100\% overlap & $80 \%$ yield & 280,000 & Failed on advancing edge of weld \\
\hline E36 - 100\% overlap & $80 \%$ yield & 877,108 & Failed on weld centreline \\
\hline E36 - 100\% overlap & $80 \%$ yield & 396,849 & Failed on advancing edge of weld \\
\hline
\end{tabular}

Insufficient fatigue data have yet been accumulated to make any useful assessment of the fatigue performance of the welds generated in this work.

\section{Conclusions}

1. Single/double sided friction stir welding of both E36 and DH36 shipbuilding steel produces lower angular and longitudinal distortion than the sub arc welding of DH36.

2. Single sided FSW in $6 \mathrm{~mm}$ thickness E36 produces similar distortion to that witnessed in single sided FSW of DH36 steel.

3. The FSW welds in E36 were at least as strong as the parent material.

4. The presence of oxide inclusions in some of the welds tested did not appear to have a detrimental effect upon weld strength.

5. Performing the fully penetrating second pass in the double side friction stir welding process creates an improvement in toughness which is likely to be related to microstructural differences.

6. From the data generated in this study supports the evidence that FSW it is a superior process to the conventional SAW process.

\section{Acknowledgments}

The authors would like to acknowledge FSW group at TWI in performing the FSW, Stuart Campbell (AMRL) in Strathclyde University in helping measuring the plate distortion. BAE Systems-Marine is acknowledged for supplying the material and funding the experimental work and C.McKechnie for producing the SAW plates and the analysis of the fatigue data by Colin Davies of Tata Steel Europe.

\section{References}

[1] Reynolds, A.P., Tang, W., Posada, M. and DeLoach, J. "Friction stir welding of DH36 steel," Science and Technology of Welding and Joining, Vol.8, No.6 (2003), pp. 455-460.

[2] Posada, M., Nguyen, J.P., Forrest, D.R., DeLoach, J.J. and DeNale, R. "Friction stir welding advances joining technology,” AMPTIAC Quarterly, Vol. 7, No.3 (2003), pp. 13-20.

[3] Posada, M. and Roush, S. "Friction stir welding - a promising new technique for joining metals," Seaframe, Vol. 1, Issue 2 (2005), pp. 17-18.

[4] McPherson, N.A., Galloway A. M., Cater S. R "A comparison between single sided friction stir welded and submerged arc welded DH36 steel thin plate", International Conference on Trends in Welding Research 2012.

[5] McPherson, N.A., Galloway A. M., Cater S. R., Osman M. M. "A comparison between single sided and double sided friction stir welded 8mm thick DH36 steel plate", International Conference on Trends in Welding Research 2012. 